\title{
Maximum QA Interval
}

National Cancer Institute

\section{Source}

National Cancer Institute. Maximum QA Interval. NCI Thesaurus. Code C120921.

The maximum time between the recording of a Q wave on ECG and the onset of the aortic blood pressure pulse. 